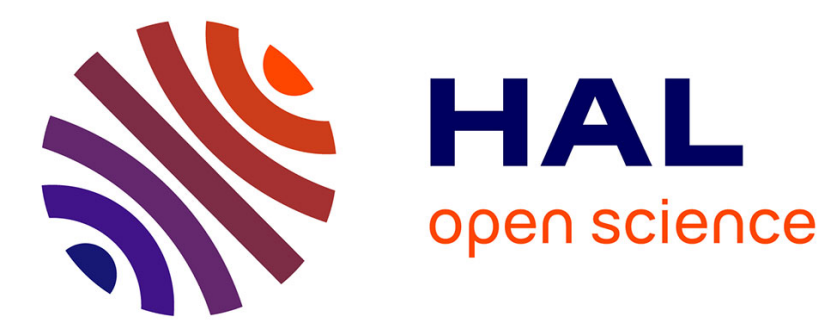

\title{
Выражение итеративности с глаголами совершенного вида прошедшего времени в русском языке
}

\author{
Tatiana Bottineau, Robert Roudet
}

\section{To cite this version:}

Tatiana Bottineau, Robert Roudet. Выражение итеративности с глаголами совершенного вида прошедшего времени в русском языке. Russian Linguistics, 2013. 〈hal-01900205〉

\section{HAL Id: hal-01900205 https://hal.science/hal-01900205}

Submitted on 21 Oct 2018

HAL is a multi-disciplinary open access archive for the deposit and dissemination of scientific research documents, whether they are published or not. The documents may come from teaching and research institutions in France or abroad, or from public or private research centers.
L'archive ouverte pluridisciplinaire HAL, est destinée au dépôt et à la diffusion de documents scientifiques de niveau recherche, publiés ou non, émanant des établissements d'enseignement et de recherche français ou étrangers, des laboratoires publics ou privés. 


\title{
Выражение итеративности с глаголами совершенного вида прошедшего времени в русском языке ${ }^{1}$
}

\author{
Tatiana Bottineau Robert Roudet
}

\begin{abstract}
The aim of this article is to define to what degree past perfective forms are compatible with iteration marks. For this purpose we will deal not only with such iteration marks as $d v a$ raza, pjat' raz, but also with such ones as často, inogda et cetera. The combination of such iteration marks často with a past perfective form is often considered as impossible, but an analysis of the linguistic reality shows that, even if rare, such schemes are not impossible. The first part of this article will deal with this point and provide an overview of all possible realizations for such syntactic constructions. The second part will deal with the question of the specific semantic value known in the linguistic literature as "summarnoe značenie" which is one of the possible values of the past perfective. We will show that such features as briefness of the process, as lack of wide temporal intervals between two phases or consecutiveness are not a compulsory condition for these schemes to be employed. From all these facts we will draw the conclusion that past perfective forms can represent a repeated process more often than usually told. Moreover, the fact that an iterative phrase like vo vsex slučajax, combines without restrictions with past perfective forms, allows us to assert that the notion of "summarnoe značenie" is not a sufficient explanation.
\end{abstract}

\section{1. Постановка вопроса. Два вида итеративности²}

Целью данной статьи является изучение сочетаемости форм прошедшего времени совершенного вида (СВ) с показателем итеративности (ПИ): такие сочетания, как он несколько раз прочитал записку считаются редким, чуть ли не маргинальным явлением в русском языке. Объясняется это тем, что подобные сочетания противоречат одному главных принципов употребления видов, сводящимся к тому, что СВ передает единичность действия.

Традиционный подход к этой проблеме опирается на понятие «суммарного значения», состоящее в том, что многократное действие якобы воспринимается как некое целое, а не как повторяющаяся реализация одного и того же действия (Mazon 1908: $222^{1}$; Бондарко 1971: 24; Маслов 2004: 106; Рассудова 1982: 38-40; Зализняк \& Шмелев 2000: 20). Даже те исследователи, которые высказывали сомнения в том, что суммарное значение является «частным значением» СВ (Гловинская 2001: 76-78; Шатуновский 2009: 296), в целом, все-таки не отрицают существования такой семантики и приписывают ее сочетанию СВ с показателями ограниченной кратности. Во всех этих работах принимаются во внимание в основном те случаи, когда итеративность выражена такими словосочетаниями как два / три раза, десять раз и т.д. Как мы постараемся показать, это употребление СВ требует уточнений, к тому же, нельзя игнорировать и сочетания прошедшего СВ с такими наречиями как часто, иногда и т. д. Следует подчеркнуть, что наша цель - определить функционирование форм прошедшего СВ с ПИ в современном русском языке, и поэтому мы будем опираться преимущественно на примеры из современных контекстов, по крайней мере в тех случаях, когда речь будет идти о нетривиальном употреблении видовременных форм.

\footnotetext{
1 Мы выражаем благодарность анонимным рецензентам, сделавшим целый ряд ценных замечаний.

2 Все примеры, кроме (26), (27), (35), взяты из НКРЯ и из различных дискуссионных блогов (Google.ru)
} 
Для адекватного освещения интересующей нас проблемы, достаточно рассматривать два вида итеративности (см. более детальный анализ понятия итеративности в Теория Функииональной Грамматики 2011: 124-152): фреквентативную и многократную итеративность. Фреквентативная итеративность не предполагает точного подсчета действий, она передается лексемами часто, иногда, редко и т.д.

Многократная же итеративность соответствует точному подсчету, и передается лексемами и словосочетаниями типа два / три раза, десять раз и т. д.

Ясно, что четкой границы между этими двумя категориями нет: такие лексемы и словосочетания как неоднократно, не раз ближе к многократной итеративности, однако они не указывают на точный подсчет. Наблюдается постепенный переход от одного полюса итеративности к другому, что можно представить на следующей шкале:

многократная
итеративность $\stackrel{\text { десять раз...-не раз / многократно...-иногда / часто... }}{\longrightarrow} \begin{aligned} & \text { фреквентативная } \\ & \text { итеративность }\end{aligned}$

Первая часть статьи посвящена сочетанию форм прошедшего СВ с показателями фреквентативной итеративности, а вторая часть - сочетанию форм прошедшего СВ с показателями многократной итеративности.

\section{2. СВ и фреквентативная итеративность}

В рамках фреквентативной итеративности следует рассматривать три разные модели в зависимости от охвата сферы действия (СДИ) показателей итеративности.

Сфера действия ПИ может не включать элемент, отвечающий за перфективность:

1. Ее конвоир все чаще начал поглядывать в сторону пригорка, похоже, утратив интерес к арестованной. (В. Быков, На болотной стежке)

2. - Она часто заморгала и поднесла скомканный платок к глазам. (Е. Парнов, Третий глаз Шивы)

В обоих примерах ясно, что речь вовсе не идет о повторном начале какого-либо действия. В качестве доказательства можно привести возможность перестановки лексем (в (1) наречие часто указывает, конечно, не на многократное начало действия, а на его частотность; не менее ясно, что приставка за- остается вне СД наречия часто).

СДИ может включать все предложение, такая модель наблюдается и с синтетическим, и с аналитическим предикатом.

Первая возможность может быть проиллюстрирована примером (3), вторая наблюдается в примере (4):

3. /../ была и академическая гостиница на улице Халтурина, где место ему всегда предоставили бы... (Л. Улицкая, Путешествие в седьмую сторону света)

4. Особенно эти чувства знакомы тем, кто часто привык проводить время на кухне или работает в офисе, где постоянно душно и жарко. (Google.ru)

\section{1. Первая модель: СДИ охватывает часть предиката}

Эту модель мы упоминаем только вскользь. Если компонент, отвечающий за перфективность, остается вне СДИ, нет никакого противоречия между принципом 
единичности действия, имплицируемым этим компонентом, и многократностью действия. Эти конструкции с нашей точки зрения являются не самыми интересными.

\section{2. Вторая модель: СДИ охватывает все предложение}

\subsection{1. Вторая модель с аналитическим предикатом}

В рамках модели с аналитическим предикатом встречаются разные конструкции, первая из них реализуется почти исключительно с модальным глаголом nрийтись $^{2}$ :

5. Mademoiselle Лебядкина, которой одно время слишком часто пришлось встречать Николая Всеволодовича, была поражена его наружностью. (Ф. Достоевский, Бесы) 6. Очень часто пришлось нам вспоминать потом эту фотографию. (В. Сидур, Памятник современному состоянию)

7. «Нам слишком часто пришлось играть в меньшинстве. Думаю, это и стало причиной поражения.» (Google.ru)

В этих примерах наблюдается почти полная, по нашему мнению, синонимия видов: часто пришлось / часто приходилось. Заметим, что наречия иногда, редко, всегда, постоянно в сочетании с глаголом прийтись не встречаются, зато возможно употребление таких ПИ, которые, в принципе, сочетаются с прошедшим СВ (каждый день, ежедневно) только в редких случаях:

8. Им каждый день пришлось получать с Земли сотни вопросов и отвечать на них. (К. Циолковский, Вне Земли)

9. Когда же пришел октябрь и в посиневшем от холода воздухе замелькали, повалили белые хлопья, занося выгон, лазины и завалинку избы, Таньке каждый день пришлось удивляться на мать. (И. Бунин, Танька)

В некоторых случаях мы затрудняемся сказать, можно ли считать, что СД охватывает все предложение или же распространяется только на вторую часть предиката. По нашему мнению, в примере (5) перестановка частей речи вызывает сомнение в равнозначности обоих высказываний: Mademoiselle Лебядкина, которой одно время пришлось слишком часто встречать Николая в семантическом плане все-таки отличается от исходной фразы, и поэтому следует признать, что в этом примере ПИ охватывает все предложение. Бывают случаи, когда изменение порядка слов совершенно очевидно ведет к изменению смысла предложения. Это утверждение можно проиллюстрировать сопоставлением следующих высказываний:

10. Ну, житель города привык часто мыться, а житель горного аула не привык... А потом я и мои коллеги задумались. ( из интернета Google)

10а. Ну, житель города часто привык мыться...

Зато в следующей фразе дело, конечно, обстоит иначе:

11. Но ближе и чаще пришлось видеть их в Белграде, на съезде эмигрантских русских писателей в 1928 году. (Б. Зайцев, Памяти Мережковского (100 лет)) 
В этом примере общей сферой действия наречий ближе и чаще является не модальный глагол пришлось, а инфинитив видеть, хотя во всех примерах, построенных по модели ПИ + пришлось + инфинитив, более естественно считать, что СДИ распространяется на предложение в целом (см. примеры 5, 6, 7, 8).

Вторая конструкция этого типа включает глагол привыкнуть:

12. С практическим подтверждением этого положения довольно часто сталкиваются врачи, ликвидируя заболевания, вызванные психогенными факторами, или, как мы чаще привыкли сльшиать, негативными стрессами. (А. Маясюк, Познай самого себя)

Замена глагола привыкнуть его квази антонимом устать не представляется возможной. Предложение $*_{\text {мы }}$ часто устали сльшиать такую болтовню воспринимается как аномальное. Интересно, что при отсутствии инфинитива сочетания глагола привыкнуть с ПИ не встречаются: ?? люди часто привыкли к этому сомнительно. Необходимым условием для таких конструкций является также присутствие элемента множественности, связанное обычно с употреблением подлежащего во множественном числе (о связи между наречиями часто, редко и присубстантивными кванторами во множественном числе см. (Булыгина, Шмелев, 1997: 40-41): мь часто привыкли сльшиать от них такое вполне приемлемое высказывание в отличие от * я часто привык сльшиать от них такое. Это связано с тем, что часто функционирует как квантификатор: мы часто привыкли слышать от них такое = многие из нас привыкли слышать от них такое. Но множественность может возникнуть не только благодаря подлежащему (в (Булыгина, Шмелев 1997) указываются случаи, когда за нее отвечает объект), но и благодаря обстоятельству:

13. Бог одарил его исключительным трудолюбием и смирением. В трудные минуты жизни он часто привык повторять слова свт. Иоанна Златоуста:/.../ (Google.ru)

Здесь часто + в трудные минуты эквивалентно в многочисленные трудные минутыл. В ряде примеров присутствие элемента множественности обусловлено контекстом и присутствует в самом предложении на имплицитном уровне. Так, в (14) часто = «у многих из нас :

14. «Но глубже этого света нашей совести, которая часто привыкла молчать потому что мы ее заглушаем, мы к ней не прислушиваемся... (митрополит Антоний, Дорожите временем, потому что дни лукавы..,).

Это условие касается сочетаний с наречием часто, с другими ПИ оно снимается:

15. И добавила, видимо, пытаясь себя немного успокоить: «Он очень вынослив, потому что всегда привык жить в плохих условиях, не избалован. (О. Головникова, Н. Тархова, И все-таки я буду историком!)

16. - Всегда привыкла готовиться только к следующему турниру. (И. Слуцкая, У нас скользкий вид спорта)

Наречие всегда здесь проявляет некоторую семантическую лабильность, в таких употреблениях наблюдается семантический сдвиг: всегда является синонимом наречия издавна. 
Третья фреквентативная конструкция включает глагол перестать:

17. Некоторое время спустя деревня неподалеку от Фрянова стала такой маленькой, что ее иногда перестали показывать на картах. (Google.ru)

18. Отсюда произошло то, что ученики иногда перестали даже его понимать. (Б. Чичерин, Воспоминания)

19. Купил компьютер, а спустя три недели он иногда перестал включаться. Что делать? (Google.ru)

Во всех этих примерах порядок следования наречия и глагола строго зафиксирован смыслом предложения; перестановка приводит к бессмыслице: ??деревня стала такой маленькой, что ее перестали иногда показывать (показывать иногда) на картах, а если и дает более или менее осмысленное предложение, то наблюдается полное изменение семантики: он иногда перестал включаться $\neq$ он перестал иногда включаться (= «он уже не включается вообще»). Напрашивается сравнение с аналитическими предикатами, включающими в себе фазисный глагол «стать» («Последнее время у меня иногда стала кружиться голова»).

В обоих случаях имеется сочетание двух смыслов :

- иногда повторяется некая ситуация.

- раньше такая ситуация не наблюдалось.

Разница заключается в том, что в одном случае итеративная ситуация выражается утвердительным предложением («голова кружится»), а в другом отрицательным («компьютер не включается»). На проблему СДИ накладывается проблема СД отрицания. При наличии глубинного отрицания охват всего предиката не равнозначен охвату зависимого инфинитива, а при отсутствии отрицания разница стирается. (Эти наблюдения были предложены рецензентом)

\subsection{2. Вторая модель с синтетическим предикатом}

Вторая модель очень часто реализуется с сослагательным наклонением (о корреляции между итеративностью и ирреальностью см. (Князев 2007: 152-157), случаев такой модели с изъявительным наклонением в современном языке относительно немного:

20. Деньги бы всегда нашлись. (В. Вересаев, К жизни)

Приравнивать формы сослагательного наклонения к формам прошедшего, в принципе, не совсем правомерно. Но заметим, тем не менее, что формы сослагательного СВ сочетаются с ПИ значительно легче, чем формы собственно прошедшего. Эта тенденция наблюдается независимо от семантики формы сослагательного:

21. Мне не надо много, хочу чтобы хоть иногда пожалел, обнял, сказал, что любит, что видит как я стараюсь для него, поцеловал! (Женщина+мужчина: Психология любви (форум))

22. Обычно я прихожу в село затемно, мокрый, голодный, а люди иногда уже собрались... (В. Шаров, Воскрешение Лазаря)

23. Все думали - когда война первый перелом прошла, отступление, эвакуация, а потом стала очень трудной жизнью, голодом стала, тоской от потери близких, иногда грязью стала, потому что не все выдерживали такое, но все же осталась жизнью, тогда думали: уж теперь-то для Нюры все. (М. Анчаров, Самшитовый лес) 
В (22), наверно, играет роль то, что рассказ ведется в настоящем времени (визуальное описание ситуации), а СВ имеет перфектное значение (оно равнозначно презенсу: «все уже в сборе»); в (23) иногда = «для некоторых». Кроме того, и здесь СВ имеет перфектное значение.

Но главное другое: уже в примере (3) место ему всегда предоставили бы ясно, что наречие всегда семантически ближе к сочетаниям в любом случае, во всех случаях. И по этому поводу следует заметить, что такие обороты как во всех / во многих случаях близки к итеративным наречиям всегда, часто..., но не требуют таких жестких ограничений на употребление $\mathrm{CB}$, как видно на следующих примерах:

24. Однако во всех случаях оказалось, что названное учреждение не имеет_свободного места /.../(О. Хвольсон, К работам /.../ С. М. Прокудин-Горский)

25. /.../она не терпит, когда говорят вздор, и в нескольких случаях заставила несчастного Игоря Викторовича сконфузиться... ( Коммерсанть-Власть)

Напрашивается вопрос, чем, к примеру, во всех случаях отличается от всегда, или чем $в$ нескольких случаях отличается от иногда? По нашему мнению, важную роль здесь играет тот факт, что во всех случаях, в отличие от всегда, индивидуализирует каждое событие, представляет цепочку отдельных друг от друга действий. Всегда, напротив, представляет их в таком свете, что они сливаются воедино, в общее множество действий, из которого не представляется возможным выделить какое-либо отдельное событие. Если согласиться, что индивидуализация каждого действия является благоприятным фактором для употребления $\mathrm{CB}$, что, между прочим, было уже замечено другими исследователями ${ }^{3}$, можно задаться вопросом, не беспочвенно ли объяснение сочетаемости ПИ так называемым суммарным значением.

\section{3. Многократная итеративность}

Многократная итеративность выражается глаголами СВ прошедшего времени только при наличии в предложении специфического показателя. Это связано с тем, что сам глагол СВ не имеет свойства передавать многократное произведение действия и означает реализацию единичного целостного действия, которое соответствует определенному событию.

К ПИ, способствующим выражению многократной итеративности, мы относим синтагмы «N раз» и временные наречия «N-ждbl», где $\mathrm{N}$ количественное числительное, a также наречие неоднократно. В отличие от фреквентативных конструкций с $\mathrm{CB}$, подобные сочетания очень часто встречаются в русском языке. Однако следует сразу же оговорить, что они употребляются и с глаголами НСВ прошедшего времени, при этом ПИ никоим образом не влияет на выбор вида глагола ${ }^{4}$.

Наиболее часто встречающиеся в сочетаниях с ПИ глаголы означают одноразовые действия (семельфактивы с суффиксом -ну-) (26) и моментальные действия (жесты или речевые акты) (27):

26. Он два раза чихнул, трижды кивнул, несколько раз стукнул по столу.

27. Он сто раз сказал, несколько раз посмотрел, два раза ударил его.

Употребление этих глаголов в итеративных предложениях создает впечатление, что названное действие было осуществлено в чрезвычайно краткий промежуток времени, сводимый к его точечному представлению на временной оси. Подобное восприятие 
может возникнуть и по отношению к временному интервалу, который разделяет сами повторяющиеся действия.

Именно такое мнение бытует в лингвистической литературе относительно так называемого «суммарного» значения глаголов $\mathrm{CB}$, при этом ПИ «N раз» и «N-жды» представляются как полноправные синонимы. Однако оба названных критерия краткость самого действия и краткость временных интервалов между его повторными реализациями, при более подробном рассмотрении конкретных примеров оказываются несостоятельными.

\section{1 Итеративность и суммарное значение}

Мы считаем, что оба вышеуказанных критерия в ряде конкретных случаев характеризуют не реально существовавшую в прошлом ситуацию, а ее субъективное восприятие говорящим. Используя критерии, такие, как порядок слов, просодия итеративного предложения и коммуникативная задача говорящего, мы ставим перед собой задачу выявить объективные параметры, характеризующие выражение многократной итеративности СВ прошедшего времени.

\section{2 Продолжительность повторявщихся действий}

Семантика глаголов СВ в ряде случаев соотносится с понятием длительности совершенного действия и не является запретом на их употребление с показателями многократной итеративности. Этот факт уже был в свое время отмечен О. Рассудовой, обратившей внимание на употребление «N раз» с глаголами $\mathrm{CB}$, образованными при помощи приставок про- и пере- (Рассудова 1982: 39).

Эти приставки, как правило, присоединяются к глагольным основам несовершенного вида, обозначающим длившиеся во времени процессы и деятельности. Семантическое значение приставки и аспектуальное значение глагольной основы находятся в соответствии друг с другом, так как образованный глагол СВ означает результат предшествовавшего ему и длившегося во времени действия: продумать, просмотреть, пройти, переплыть, переночевать.

Приставка про- имплицирует продвижение в пространстве или во времени, то есть предполагает прохождение некоего конкретного (пространственного) или абстрактного (временного) интервала, как правило, ограниченного определенными рамками. Образованные с еe помощью глаголы CВ означают полностью реализованное единичное действие $(28,29,30)$ или выражают качественно-результативный образ действия, ведущего к изменению состояния объекта действия $(31)^{5}$ :

28. Я прошёлся два раза по комнате, открыл окно, включил вентилятор и остановился около него. (Ю. Домбровский, Хранитель древностей)

29. Однако на форумах рекламщиков уже неоднократно прозвучала мысль о том, что кампания оказалась безрезультатной. (Google.ru)

30. Я очень любил вообще изображения животных, знал, никогда их не видя, множество пород диких зверей и три тома Брэма прочёл два раза с начала и до конца. (Г. А. Газданов. Вечер у Клэр)

31. Я два раза прокипятила ягоды, засыпала сахаром и получился замечательный сироп. (Google.ru) 
Совершенный вид глаголов в этих примерах указывает на то, что начатый процесс достиг своего естественного предела, а приставки выражают существование временного или пространственного интервала, протяженность которого часто уточняется контекстом. Так, в (28) протяженность действия прошелся ограничивается сирконстантом по комнате; в (29) выражение мысли, которое обозначает глагол прозвучала требует минимального времени; в (30) действие прочел измеряется количеством томов и указанием на то, что они были прочитаны с начала и до конца. Запрета на повторное осуществление длившихся во времени и достигших своего предела процессов в этих предложениях не наблюдается.

Подобное замечание может быть сделано по поводу итеративного употребления

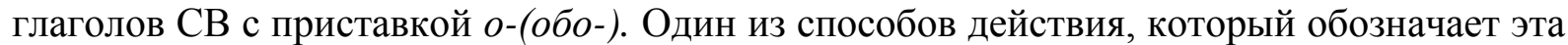
приставка, связан с идеей осуществления оборота вокруг чего-либо, проведения действия по полной окружности. Глаголы с этой приставкой означают реализацию акта в его целостности, поскольку невозможно обойти вокруг чего-то, не совершив при этом оборота на 360 градусов:

32. /.../ Я остановился и два раза описал рукой светящуюся дугу (глупее, конечно, ничего уж нельзя было придумать), и другой фонарик проделал то же самое. (Ю. Домбровский, Хранитель древностей)

33. Ревизор! Списать на берег га-асподина мичмана! Ступайте! - и капитан повернулся к гостям. Он не видел, как мичман большими, журавлиными шагами описал на палубе дугу, обошёл для чего-то трюмный люк два раза вокруг и не понимая, почему это он шагает, пошёл к сходне. (Б. Житков , «Сию минуту-с!..»)

34. На спидометрах таких машин от 300 тысяч километров и больше. Они не раз обогнули_земной шар. (Новости)

В (32) действие описал рукой соответствует кругообразному жесту, осуществленному два раза в ограниченном пространстве, но, вероятно, занявшему небольшой промежуток времени; в (33) действие обошел тюремный люк, также совершенное дважды в определенном пространстве и потребовало более продолжительного времени; в (34) повторявшееся действие заняло, несомненно, значительный временной интервал. При этом сама по себе продолжительность временного интервала в этих примерах никак не влияет на выражение итеративности действия.

Приведенные примеры показывают, что при выражении итерации формами СВ прошедшего времени критерий краткости временного интервала, занимаемого повторявшимся действием, не может считаться релевантным.

\section{3 Продолжительность интервала между повторявщимися действиями}

Вторым значимым признаком суммарного значения СВ традиционно считается краткость временных интервалов между отдельными реализациями повторявшегося в прошлом действия, а также стирание границ между ними. Состоятельность этого критерия также вызывает сомнения.

35. - Ведь сто раз уже сказал! Почему не слушаешься! 
В примере (35) ПИ сто раз употребляется в качестве гиперболы. Речь идет о выражении неудовольствия говорящего тем, что многократное действие не привело к ожидаемому результату, что и подтверждается в следующем предложении. При этом понятно, что повторная реализация одного и того же действия каждый раз имела место в различных ситуациях, но при схожих условиях. Таким образом, говорящий имплицитно актуализирует каждое отдельное неоднократно существовавшее в прошлом действие, а отнюдь не сводит их к единому событию, как это принято утверждать в лингвистической литературе при определении суммарного значения СВ. Формальные параметры в следующем примере с «ПИ + « $\mathrm{N}$ раз»» подтверждают индивидуализацию каждого отдельного действия:

36. Во время дефиле модель упала три $\downarrow$ раза. Она сделала это трижды. Видимо, чтото не так с платьем. (Google.ru)

Размещение «N раз» в финальной позиции указывает на то, что именно этот элемент предложения несет на себе самую большую информативную нагрузку. Это отмечается падающим на него фразовым ударением, которое несет на себе последний элемент синтагмы три раза и которое мы обозначаем знаком $(\downarrow)$. Внимание привлекается не к факту падения субъекта, а к тому, что субъект упал именно три раза.

При употреблении квантификатора в препозиции к глаголу сообщение о серии падений субъекта имело бы банальный характер, и по правилам размещения ударения в утвердительном предложении информативная нагрузка была бы перенесена на последний элемент предложения, в данном случае, глагол:

36а. Во время дефиле модель три раза $\downarrow$ упала.

В примере (36) можно представить себе, что падения модели во время показа мод последовали сразу же одно за другим и в таком случае, маркеры три раза и трижды следовало бы считать полноправными синонимами. Но можно также представить себе, что между каждым падением модель все-таки сделала несколько шагов или же упала на разных этапах дефиле: в начале, во время его прохождения, в конце показа мод. Вполне возможно, что причины падений были самыми разнообразными - девушка могла споткнуться, наступить на платье, сломать каблук и т.д. Интервалы между повторявшимися действиями в таком случае не только могут быть разделены более или менее длительными промежутками времени, но и сами по себе не обязательно имеют равномерный по времени характер.

Уже само существование интервала между каждым отдельным действием способствует его индивидуализации и отсылает к определенным условиям, в которых имело место каждое отдельное действие, то есть к какой-то одной конкретной ситуации.

Это подтверждается и семантизмом существительного раз, имплицитно актуализирующим существование каждой специфической ситуации, в которой имело одно и то же действие. Локализация действий на оси времени не указывается, что придает итеративным предложениям оттенок неопределенности, но, тем не менее, она вполне может быть восстановлена:

36б. Во время дефиле модель упала три раза: первый раз в начале показа, второй раз в момент выхода со сцены и в третий раз, когда она вышла приветствовать публику.

Учитывая эти факторы, мы полагаем, что сочетание «N раз + глагол СВ прошедшего времени» обособляет отдельные «кванты» серии одного и того же действия и 
партикуляризирует каждое из них: действительность описывается как состоящая из отдельных микро-ситуаций, последовательно следующих одна за другой. По нашему мнению, не представляется возможным считать, что эта конструкция сводит повторные действия к какому-то единому акту, существование которого в этом контексте невозможно перефразировать. В связи с этим, мы полагаем, что речь здесь идет об итерации независимых, но схожих событий, организованных в последовательную цепь, имевшую место на протяжении единого временного интервала, соответствующего в реальности одной ситуации.

Та же самая ситуация представлена иначе при использовании конструкции « $\mathrm{N}-ж \partial b l+$ $\mathrm{CB}$ в в предложении, содержащем наречие триждыл. В приведенном примере этот ПИ также размещен в финальной позиции и несет на себе главную информативную нагрузку. Тем не менее, он употреблен вслед за предложением, в котором информация о троекратном падении субъекта уже дана и которое служит ему темой. Информация заключаются не в сообщении о падениях субъекта, а в подтверждении, что действие действительно имело место три раза.

В предложении с « $\mathrm{N}$ раз» описание ситуации вполне может показаться неправдоподобным и вызвать сомнение. «N-жды» во втором предложении имеет двойную функцию: с одной стороны, трижды подводит количественный итог событиям, а с другой стороны, подтверждает его адекватность реальным фактам, квантификация которых при помощи « $\mathrm{N}$ раз» может показаться преувеличенной. ${ }^{6}$ Речь идет, таким образом, не столько об исчислении многократно совершенного действия, а о подтверждении в случае возможной полемики уже данной на этот счет информации.

Если в отношении трижды можно утверждать, что ситуация представлена глобально и глагол употреблен в суммарном значении, соответствующем целостности восприятия всей ситуации, то в отношении три раза такое утверждение не является обоснованным. Это различие можно проследить на следующем примере:

37. В своем дневнике я записывал все впечатления от спектаклей - я жил этим. Когда в 1935 году я $\downarrow$ дажды посмотрел во МХАТе спектакль «Платон $\downarrow$ Кречет»/.../то был настолько потрясен игрой артистов - Добронравова, Грибкова и Топоркова, - что даже написал об этом письмо в «Пионерскую правду» /.../. Вот это письмо: «Я два раза смотрел постановку «Платон $\downarrow$ Кречет» в филиале Художественного театра. Я очень рад, /.../ (В. Давыдов, Театр моей мечты)

Употребление наречия дважды в придаточном предложении и с указанием точной временной локализации событий (в 1935 году) представляется как итог ситуации (я дважды посмотрел спектакль), повлекший за собой последствия, изложенные в главном предложении (был потрясен). В предложении отмечается наличие дополнительного ударения слабой интенсивности на ПИ дважды, употребленном в препозиции к глаголу. Это ударение способствует его акцентному выделению и подчеркивает важность квантификации действия, а не его существования.

В связи с этим, замена глагола $\mathrm{CB}$ на глагол $\mathrm{HCB}$ в его конкретно-фактическом значении здесь не представляется возможной:

37а. *Когда в 1935 году я дважды смотрел во МХАТе спектакль «Платон Кречет», то был настолько потрясен игрой артистов - Добронравова, Грибкова и Топоркова, - что даже написал об этом письмо в «Пионерскую правду».

Тем не менее, во второй части контекста глагол НСВ употреблен именно в конкретнофактическом значении, позволяющем «выразить неоднократное воспроизведение 
одного и того же действия» (Рассудова 1982: 38). Фразовое ударение падает на расположенный в финальной позиции элемент Платон Кречет, ПИ два раза не несет на себе акцентной маркировки, а это свидетельствует о том, что количественной характеристике повторявшегося действия особенного внимания не уделяется.

Это употребление НСВ сближается со значением СВ и с выражением реализации единичного действия, поэтому замена одного глагола другим вполне допустима. При этом следует еще раз уточнить, что вид глагола определяется не выбором ПИ «N раз» или «N-жды», а зависит от коммуникативной задачи говорящего:

37б. Вот это письмо: «Я два раза посмотрел постановку «Платон Кречет» в филиале Художественного театра. Я очень рад, что в этом театре так хорошо играют артисты. Хочу их поблагодарить. Когда я вырасту, то буду артистом именно в этом театре.

Итак, употребление «N раз» и «N-жды» в одном контексте и по отношению к одной и той же ситуации отражает разный подход в ее описании и иллюстрирует неполное семантическое совпадение этих ПИ. «N раз» выступает как маркер индивидуализации каждого отдельного действия в качестве единичного события, которое повторилось в одной ситуации. «N-жды», наоборот, подводит окончательный итог итерации одного и того же действия, но при этом привносит в высказывание субъективную оценку. «Nжды» отражает существование скрытого контраста на уровне квантификации действия и выступает как гарант адекватности описанной ситуации реально имевшим место событиям. Описанное функционирование «N-жды» имплицирует его акцентное или позиционное выделение как наиболее важного информативного элемента в предложении. Так, в (36) контраст получает следующую перефразировку: «трудно поверить, но модель действительно упала три раза». В (37) существующий контраст относится скорее к самой квантификации повторявшегося действия: «спектакль так понравился расссказчику, что он смотрел его не один, а два раза» ${ }^{7}$.

Этот вывод позволяет разделить показатели итеративной итеративности, сочетающиеся с глаголами $\mathrm{CB}$ прошедшего времени, на две категории: «N раз» как нейтральные квантификаторы многократной итеративности и «N-жды» как показатели суммарной итеративности, служащие гарантами адекватности квантификации многократного действия.

\section{4 Последовательность повторивщихся в прошлом действий и дистрибутивная итерация}

Как было отмечено, многократная итеративность, выражаемая сочетаниями глаголов $\mathrm{CB}$ прошедшего времени с показателями «N раз», связана с идеей расчленения одного временного интервала на несколько идентичных отрезков. Это замечание относится к действиям, направленным на один и тот же актант, будь то субъект или объект действия. В таком случае, может создаться впечатление их обязательной непосредственной последовательности во времени. Употребление наречия подряд, на первый взгляд, подтверждает эту точку зрения:

38. В Пермском крае воришка два раза подряд ограбил киоскера. Первый раз он ограбил киоск еще 14 марта. Женщина не стала обращаться в полицию и через некоторое время мошенник, почувствовав безнаказанность, вновь пошел на грабеж. (Google.ru) 
39. «МЮ» выиграл три раза подряд. Лидер чемпионата Англии по футболу «Манчестер Юнайтед» одержал третью подряд победу, обыграв на своем поле «Фулхэм». (Google.ru)

40. Всё это время ежу казалось ${ }^{8}$, что он уже умер, причем умер много раз подряд. (Google.ru)

Словарь Т. Ефремовой (2000) дает наречию подряд следующее определение: «последовательно, один за другим. В продолжение какого-либо отрезка времени, расстояния; без перерыва».

В определении подчеркивается привносимый наречием эффект стирания временного интервала между повторными действиями. Однако, как показывает сирконстант через некоторое время в примере (38), протяженность интервала может быть и относительно значительной.

На наш взгляд, подряд указывает не на отсутствие интервала, а на субъективное восприятие этого интервала говорящим. Говорящему важно не реально истекшее между отдельными действиями время, а отсутствие события, которое могло бы воспрепятствовать итерации названного действия и его включению в последовательную цепь однородных актов. Так, в (38) это отсутствие жалобы потерпевших в полицию; в (39) - отсутствие проигрышей между тремя одержанными во время чемпионата победами. В (40) глагол казалось недвусмысленно указывает, что речь идет не о реально повторившихся событиях, а о том, как их воспринимает субъект, который думает, что ему пришлось пережить смерть столько же раз, сколько раз его жизнь подвергалась угрозе.

Подряд, таким образом, имплицитно вводит в высказывание идею непрерываемой последовательности событий, существовавших в одном временном интервале. Итеративность получает однородный характер, но при этом не может приравниваться к с суммарному значению. Так, в первых двух примерах выделяется и описывается какаято одна из повторившихся ситуаций - первый грабеж, третья победа.

Надо отметить интересный и показательный факт, что наблюдается запрет на сочетаемость наречия подряд с ПИ типа «N-жды».

При выражении итерации действие может быть направлено и на разные объекты. В таком случае, речь идет не о повторных действиях, которые заполняют один и тот же временной интервал, а о ситуациях, имевших место в разные временные интервалы, разделенные более продолжительными промежутками времени:

41. /.../я вышел к народу и сказал: «Вот что случилось - два раза подряд какой-то человек во время богослужения украл иконыл. Мы можем отнестись к этому двояко: или видеть в этом кощунство и молить Бога, чтобы Он наказал преступника, или задуматься над тем, что может человека побудить совершить такое дело. /.../(митрополит Антоний, Праздник иконы Божией Матери Нечаянная Радость)

Мы имеем здесь пример дистрибутивной итерации, когда действие было направлено на различные актанты и произошло в различные временные интервалы. Этим пример отличается от предшествующих контекстов, в которых многократное действие было обращено на один и тот же актант, субъект (команда, еж) или объект (киоскер). На это указывает прежде всего употребление во множественном числе дополнения иконы, заменить которое дополнением в единственном числе не представляется возможным:

41а. *Вот что случилось - два раза подряд какой-то человек во время богослужения украл икону. 
Имея в виду, что в приведенных примерах одно и то же повторявшееся действие имело место в разные периоды времени, мы считаем, что дистрибутивная итеративность является вариантом многократной итеративности, от которого она отличается присутствием компонентом «множественное/единственное число» актанта.

Эти же признаки сближают многократную итеративность с фреквентативной, когда одно и то же действие было осуществлено различными субъектами в разные периоды времени или же было направлено на разные объекты.

\section{4. Вместо заключения}

Рассмотренные примеры подтверждают неоднородный характер самого понятия итеративности, отсылающего к различным типам итерации одного и того же действия: фреквентативной итеративности (часто, иногда и т.д.), многократной («N раз») и суммарной итеративности («N-жды»).

При фреквентативной итерации наблюдается итерация ситуаций и временных интервалов, в которых имело место одно и то же действие, а при многократной итеративности одно и то же действие повторно реализовалось в едином временном интервале.

Самым наглядным доказательством неадекватности принятого в литературе определения так называемого «суммарного значения» СВ является параллель между фреквентативной итерацией с ПИ во всех случаях и многократной итерацией с ПИ «N раз».

Суммарное значение $\mathrm{CB}$, в нашем понимании, выражается сочетаниями глагола СВ с ПИ «N-жды» и соответствует не сведению многократного действия к единому акту, а подведению окончательного и неоспоримого итога итерации. Наличие имплицитного контраста на уровне квантификации действия подтверждается анализом формальных и просодических характеристик предложений с показателями «N-жды».

Во всех перечисленных конфигурациях глагол СВ прошедшего времени употребляется в своем основном аспектуальном значении и обозначает итерацию тождественных событий, каждое из которых было реализовано как отдельный самостоятельный акт. Их итерация выражается не глаголом СВ, а контекстуальным окружением и ПИ, который, в итоге, является основным составляющим элементом итеративной синтагмы. Эти наблюдения являются подтверждением того, что, как уже неоднократно отмечалось в литературе, в иерархии видовых черт критерий единичности действия стоит ниже критерия целостности действия, ибо настоящей несовместимости между СВ и итеративностью не наблюдается.

\footnotetext{
${ }^{1}$ « Action réitérée ramenée à l'unité »

2 с глаголом суметь у нас всего один пример: «Автор приносит читателю извинения в том, что в книге, построенной на документальных свидетельствах разных людей, он иногда не сумел избежать повторений (...) » (3. Масленикова, 1992, Жизнь отца Александра Меня)

3 см. Шатуновский 2009: 298 «... цепочка глаголов СВ конкретизирует, детализирует отдельный квант повторяющегося события, описывая составляющие его более конкретные и «мелкие» события...». Правда, тут речь идет об употреблении настоящего СВ.

${ }^{4}$ Выбор вида определяется, прежде всего, смыслом контекста и коммуникативной задачей говорящего. Эта проблема не входит в круг вопросов, затрагиваемых в этой статье.

5 Термин «качественно-результативный способ действия» заимствован у А. В. Бондарко (Теория функииональной грамматики, 2011, стр. 78). Глагол прокипятить не имеет собственно временного значения, однако обозначает завершившийся процесс, приведший к изменению состояния объекта, и
} 
употребляется в перфектном значении. Достижение новой ситуации требует определенного времени, и значение приставки дублирует семантический компонент, присутствующий в глагольной основе.

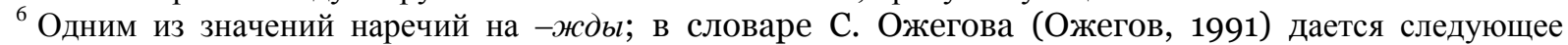
определение выражения как дважды два - о том, что совершенно бесспорно, ясно. Трижды подчеркивает истинность и полноту признака.

${ }^{7}$ Комментарий к примеру (36) был предложен рецензентом статьи.

${ }^{8}$ Речь идет о постоянно возобновлявшихся и разнообразных попытках волка съесть спрятавшегося в своей норе ежа.

Библиография

Бондарко А.В., 1971, Вид и время русского глагола, Москва.

Булыгина Т.В., Шмелев А.Д., 1997, Языковая концептуализаџия мира (на материале русской грамматики), Москва, Языки русской культуры.

Гловинская М., 2001, Многозначность и синонимия в видо-временной системе русского языка, Москва, Азбуковник, Русские словари.

Грамматика русского языка, под ред. Н, Шведовой, 1982, Москва, Наука, Институт русского

языка им. В. В, Виноградова - АН СССР.

Ефремова Т. Ф., 2000, Новый словарь русского языка. Толково-словообразовательный, Москва, Русский язык.

Зализняк А. А., Шмелев А.Д., 2000, Введение в русскую аспектологию, Москва, Языки русской культуры.

Князев Ю.П., 2007, Грамматическая семантика, Москва, Языки славянских культур

Маслов Ю.С., 2004, Избранные труды, Москва, Языки славянской культуры.

Рассудова О.П., 1982, Употребление видов глагола в современном русском языке, Москва, Русский язык.

Фичи Ф., 2004, «О некоторых атипичных употребления презенса СВ в русском языке », in Сокровенные смыслы, сборник статей в честь Н.Д. Арутюновой, Москва, Языки славянских культур, стр. 344-355

Теория функииональной грамматики, Введение. Аспектуальность. Временная локализованность. Таксис., 2011, Москва, УРСС.

Храковский В. С., «Типология семельфактива», in Типология вида. Проблемы, поиски, решения. Москва, Языки русской культуры.

Шатуновский И. Б., 2009, Проблемы русского вида, Москва, Языки славянских культур.

Fontaine J., 1983, Grammaire du texte et aspect du verbe en russe contemporain, Paris, Institut d'Études Slaves.

Guiraud-Weber M., 2004, L'aspect du verbe russe, Aix-en-Provence, Presses Universitaires de Provence.

Mazon A., 1908, Aspects du verbe russe, Paris. 